\title{
Utilizing $\mathrm{CaCO}_{3}, \mathrm{CaF}_{2}, \mathrm{SiO}_{2}$, and $\mathrm{TiO}_{2}$ particles to enhance color homogeneity and luminous flux of WLEDs
}

\author{
Nguyen Thi Phuong Loan', Nguyen Doan Quoc Anh' \\ ${ }^{1}$ Faculty of Fundamental 2, Posts and Telecommunications Institute of Technology, Vietnam \\ ${ }^{2}$ Power System Optimization Research Group, Faculty of Electrical and Electronics Engineering, \\ Ton Duc Thang University, Vietnam
}

\begin{tabular}{l} 
Article Info \\
\hline Article history: \\
Received Sep 4, 2019 \\
Revised Apr 27, 2020 \\
Accepted May 7, 2020 \\
\hline
\end{tabular}

Keywords:

$\mathrm{CaCO}_{3}$

$\mathrm{CaF}_{2}$

Luminous flux

Mie-scattering theory

$\mathrm{SiO}_{2}$

$\mathrm{TiO}_{2}$

\begin{abstract}
The chromatic homogeneity and luminous efficiency are two crucial elements for determining a high-quality phosphor-converted LEDs (pc-LEDs). Thus, this paper provides essential information in choosing the particles to enhance lighting properties of high performance pc-LEDs. Scattering enhancement particles (SEP) such as $\mathrm{CaCO}_{3}, \mathrm{CaF}_{2}, \mathrm{SiO}_{2}$, and $\mathrm{TiO}_{2}$, are combined with yellow phosphor $\mathrm{Y}_{3} \mathrm{Al}_{5} \mathrm{O}_{12}: \mathrm{Ce}^{3+}$ and applied to the lighting devices. Initially, optical simulations are carried out with the support of LightTools program. Next, the Mie-theory is applied to calculate and confirm the results. The calculation subjects are SEPs scattering properties within the band $455-595 \mathrm{~nm}$. The scattering results of $\mathrm{TiO}_{2}$ suggest it is the optimal choice for pc-LEDs color quality in comparison to the other SEPs; however, it causes the luminous flux to decrease significantly along with the increase in its concentration. Besides, with the addition of $\mathrm{SiO}_{2}$ grains, we can accomplish higher lumen output at all particle sizes. Meanwhile, the application of $30 \% \mathrm{CaCO}_{3}$ can decreas the CCT deviation by $620 \mathrm{~K}$ making $\mathrm{CaCO}_{3}$ the potential particle to be selected for chromatic quality and light output enhancement of pc-LEDs.
\end{abstract}

Copyright $\odot 2020$ Institute of Advanced Engineering and Science. All rights reserved.

\section{Corresponding Author:}

Nguyen Doan Quoc Anh,

Power System Optimization Research Group,

Faculty of Electrical and Electronics Engineering,

Ton Duc Thang University,

No. 19 Nguyen Huu Tho Street, Tan Phong Ward, District 7, Ho Chi Minh City, Vietnam.

Email: nguyendoanquocanh@tdtu.edu.vn

\section{INTRODUCTION}

The construction of pc-LEDs is a crucial process that many changes can be made to directly affect the critical quality indicator such as including chromatic quality, luminous flux, and the color rendering index [1-3]. Ordinarily, a pc-LED is established by combining yellow $\mathrm{Y}_{3} \mathrm{Al}_{5} \mathrm{O}_{12}$ : $\mathrm{Ce}^{3+}$ phosphor with silicone glue. White light with desired color condition is created by the process in which the exciting blue light is absorbed by $\mathrm{Y}_{3} \mathrm{Al}_{5} \mathrm{O}_{12}: \mathrm{Ce}^{3+}$ phosphor from the chips and after that, the yellow light is stimulated [4]. As the radiant intensity distribution of phosphor-scattered blue light disagrees with that of the phosphoremitted yellow light, it leads to the inhomogeneous spatial color distribution [5]. Subsequently, a circular yellowish layer appears in lighting devices constructed from the conformal coating method, the effect of such outcome is presented in this manuscript, which verifies that it causes discomfort to human eyes. More clearly, when the blue light is absorbed by phosphor during the scattering process, its power becomes weaker. However, the increase of scattering events in WLEDs allows the energy of converted yellow light to rise, due to the complete difference between the wavelengths and range and components in the phosphor layer. After we capture that key, we have effectively used it in the change of spatial color homogeneity of pc-LEDs. The compound of $\mathrm{SiO}_{2}, \mathrm{~B}_{2} \mathrm{O}_{3}, \mathrm{PbO}$ in-glass phosphor, yellow phosphor particles bounded by silicone is effective in reducing color deviation of $6000 \mathrm{~K}$ devices by $590 \mathrm{~K}$ [6-9]. Meanwhile, Lin's group fabricated 
the $\mathrm{HfO}_{2} / \mathrm{SiO}_{2}$ DBR film that can lower the chromatic deflection at $5000 \mathrm{~K}$ average CCT by $1474 \mathrm{~K}$ from $1758 \mathrm{~K}$ [10]. Moreover, applying the remote structure with patterned phosphor layer is reported to retain the color temperature deflection of $5537 \mathrm{~K}$ color temperature devices at $441 \mathrm{~K}$ [11]. The innovative structure modifications really benefits the enhancement of spatial color homogeneity, however, the fabrication process of these configurations is complex and the manufacturing cost is also high. Therefore, more practical materials which are SEPs such as $\mathrm{TiO}_{2}$ [12], $\mathrm{ZrO}_{2}$ [13], microspheres [14] and $\mathrm{SiO}_{2}$ [15-17] have been chosen as an alternative to combine into the $\mathrm{Y}_{3} \mathrm{Al}_{5} \mathrm{O}_{12}: \mathrm{Ce}^{3+}$ layer and create a new scattering compound. The report published in 2010 by Lee and his partner applied Titania $\left(\mathrm{TiO}_{2}\right)$ particles as scattering material for pc-LEDs. The results of this particular research evaluate the effectiveness of phosphor layer doped with $0.1 \% \mathrm{TiO}_{2}$ in generating higher color homogeneity [18]. In another research of Chen and his partners, $\mathrm{TiO}_{2}$ diffuser-loaded encapsulation to enhance the CCT uniformity and reduce the CCT variance in remote phosphor white LEDs. Their experimental results show that with $\mathrm{TiO}_{2}$ diffuser applied, the angular color uniformity could be increased by $31.82 \%$, and the luminous flux was leveled up by $8.65 \%$. Besides, a recent study of Liang et al., stated $\mathrm{TiO}_{2}$ being catalytic that providing persistent and unlimited oxidizing agent is a potential treatment for dangerous contaminant substance, such as $\mathrm{UV} / \mathrm{TiO}_{2}$ for microcystins. Therefore, this also strengthens the use of $\mathrm{TiO}_{2}$ in lighting applications. Besides, $\mathrm{CaF}_{2}$ combined with other patterned phosphor for better WLEDs acquired plenty of attentions from researchers because of the outstanding lighting characteristics and heating performance of $\mathrm{CaF}_{2}$. In 2018, Bhanvase et al. also presented the optical and structural properties of $\mathrm{CaF}_{2}: \mathrm{Eu}^{3+}$ which was synthesized by using ultrasound assisted method. They concluded in the study that this $\mathrm{CaF}_{2}: \mathrm{Eu}^{3+}$ phosphor seems to be a good red emitting material as its excitation band agrees with the excitation range of LED and $\mathrm{Eu}^{3+}$ ions show the excitation band peaking at $394 \mathrm{~nm}$ and at $591 \mathrm{~nm}$ as well as $612 \mathrm{~nm}$ for transmission spectrum, respectively. Then, Xie and Wang's team report in 2019 introduced a new phosphor ceramic composite consists of YAG:Ce that emits yellow light and none light-emitting $\mathrm{CaF}_{2}$ ceramic material called $\mathrm{CaF}_{2}-\mathrm{YAG}: \mathrm{Ce}$. They found that using $\mathrm{CaF}_{2}-\mathrm{YAG}$ :Ce phosphor ceramic could help WLEDs increase their optical properties: lumen output $=359.7 \mathrm{~lm}$, color temperature in between $4021 \mathrm{~K}$ and $7941 \mathrm{~K}$, and color rendering index from 70.1 to 82.7 . In contrast, they also mentioned the disadvantage of excessively increasing thickness of this ceramic which is the decrease in luminous flux. Another study analyzing the effect of $\mathrm{CaCO}_{3}$ concluded that with $10 \%$ concentration of $\mathrm{CaCO}_{3}$, the spatial chromatic homogeneity can increase considerably. Besides, $\mathrm{SiO}_{2}$ grains is known to be a potential material in controlling the overall chromatic consistency of lighting devices. Furthermore, researchers have shown some pieces of evidence to verify the potential connection of $\mathrm{SiO}_{2}$ particles arrangement within the scattering compound and chromatic results. Apart from particles position, the chromatic performance of pc-LEDs is subjected to $\mathrm{SiO}_{2}$ particle magnitude as well [19-21]. The new composite they proposed was nanoplate constituted by $\mathrm{QDs}-\mathrm{SiO}_{2}-\mathrm{BN}$ that could accomplish reduce heating issues and improve QDs consistency in compound.

The above studies have suggested that the influence of SEPs on the color performance of pc-LED is so great. However, these researches just focus on one specific SEP, in other words they do not cover all the pros and cons of the other ones, and thus, the emerging issue is that which material will be the most appropriate SEP that can better both color uniformity and brightness of pc-LEDs. In addition, through previous studies, the benefits of SEPs including the reduction in color deviation and lumen efficacy improvement in one-chip lighting configuration at low color temperature, are undeniable. Using appropriate amount SEPs along suitable size benefits the lighting properties of pc-LEDs. Therefore, based on the results of aforementioned articles and our own investigations, this study will provide details about the impacts of SEPs with different concentrations on WLEDs and then make specific comparisons to give manufacturers suitable selections of SEPs for their LED products.

In this study, we specifically opened a study for a variety of SEPs including $\mathrm{CaCO}_{3}, \mathrm{CaF}_{2}, \mathrm{SiO}_{2}$, and $\mathrm{TiO}_{2}$. These phosphor particles are commonly used to produce a higher quality of pc-LEDs. Not only does this paper determines the best selection of SEP, but also explains in details why SEPs can promote two optical characteristics of WLEDs using results yielded from mathematical calculation. Besides, the contents of this research are divided into 4 parts with Section 1 for general introduction, section 2 explains mathematical model to compute scattering properties of the materials, section 3 provides the detailed optical experiments, aiming at this paper's objectives, and some discussions on the experimental outcomes and finally, section 4 shows the article summary.

\section{SCATTERING ANALYSIS}

According to Mie-scattering theory, when the SEPs in conformal phosphor pc-LEDs structure induce light scattering, at that time the effect will be determined by apply a calculating tool called MATLAB [22-25]. The equations applied to calculate the scattering coefficient $\mu_{s c a}(\lambda)$, the anisotropy factor $g(\lambda)$, the reduced scattering coefficient $\delta_{\text {sca }}(\lambda)$ and the scattering amplitude functions $S_{l}(\theta)$ and $S_{2}(\theta)$ are presented as follows:

Int J Elec \& Comp Eng, Vol. 10, No. 5, October 2020 : 5175 - 5182 


$$
\begin{aligned}
& \mu_{s c a}(\lambda)=\int N(r) C_{s c a}(\lambda, r) d r \\
& g(\lambda)=2 \pi \iint_{-1}^{1} p(\theta, \lambda, r) f(r) \cos \theta d \cos \theta d r \\
& \delta_{s c a}=\mu_{s c a}(1-g) \\
& S_{1}=\sum_{n=1}^{\infty} \frac{2 n+1}{n(n+1)}\left[a_{n}(x, m) \pi_{n}(\cos \theta)+b_{n}(x, m) \tau_{n}(\cos \theta)\right] \\
& S_{2}=\sum_{n=1}^{\infty} \frac{2 n+1}{n(n+1)}\left[a_{n}(x, m) \tau_{n}(\cos \theta)+b_{n}(x, m) \pi_{n}(\cos \theta)\right]
\end{aligned}
$$

where, $N(r)$ represents the amount of scattering particles $\left(\right.$ per $\left.\mathrm{mm}^{3}\right) . C_{s c a}$ is the scattering cross section $\left(\mathrm{mm}^{2}\right)$. The wavelength of incident light is expressed by $\lambda(\mathrm{nm})$. The parameter of particles size is $r$ for radius (mm). The degree in which the scattering event occurs is depicted by $\theta$. the phase function is shown as $p(\theta, \lambda, r)$ while the function for SEP size distribution in phosphor film is $f(r)$. The expansion coefficient for even and odd symmetry are respectively as $a_{n}$ and $b_{n}$. $x$ is the size parameter, $m$ is index of refraction. $\pi_{n}(\cos \theta)$ and $\tau_{n}(\cos \theta)$ are the functions for dependence in angular.

Diagrams of Figures 1 and 2 demonstrate the benefits of dissipating coefficients, which increment together with the SEP focus. In the bar outline, it is additionally indicated that at high SEPs' concentrations, the effect of the blue light absorption is also stronger. Among the SEPs, there is no contender which can pass $\mathrm{CaCO}_{3}$ particles in giving the dissipating coefficient. Moreover, with the presence of $\mathrm{CaCO}_{3}$, the distinction of dissipating coefficients between the wavelengths of $455 \mathrm{~nm}$ and $595 \mathrm{~nm}$ is inconsequential. This implies that $\mathrm{CaCO}_{3}$ particles are effective in managing the transmission coefficient of blue chips and yellow phosphor. The theoretical $\mathrm{g}(\lambda)$ of blue and yellow chromatic radiation yielded from (2) are expressed in Figures 2 and 3. Similar to coefficient of dispersion, the anisotropy factor $g(\lambda)$ is non-responsive to properties of SEPs. The influence that SEP thickness has on $g(\lambda)$ expansion is often overlooked due to the insignificant nature of the effect.

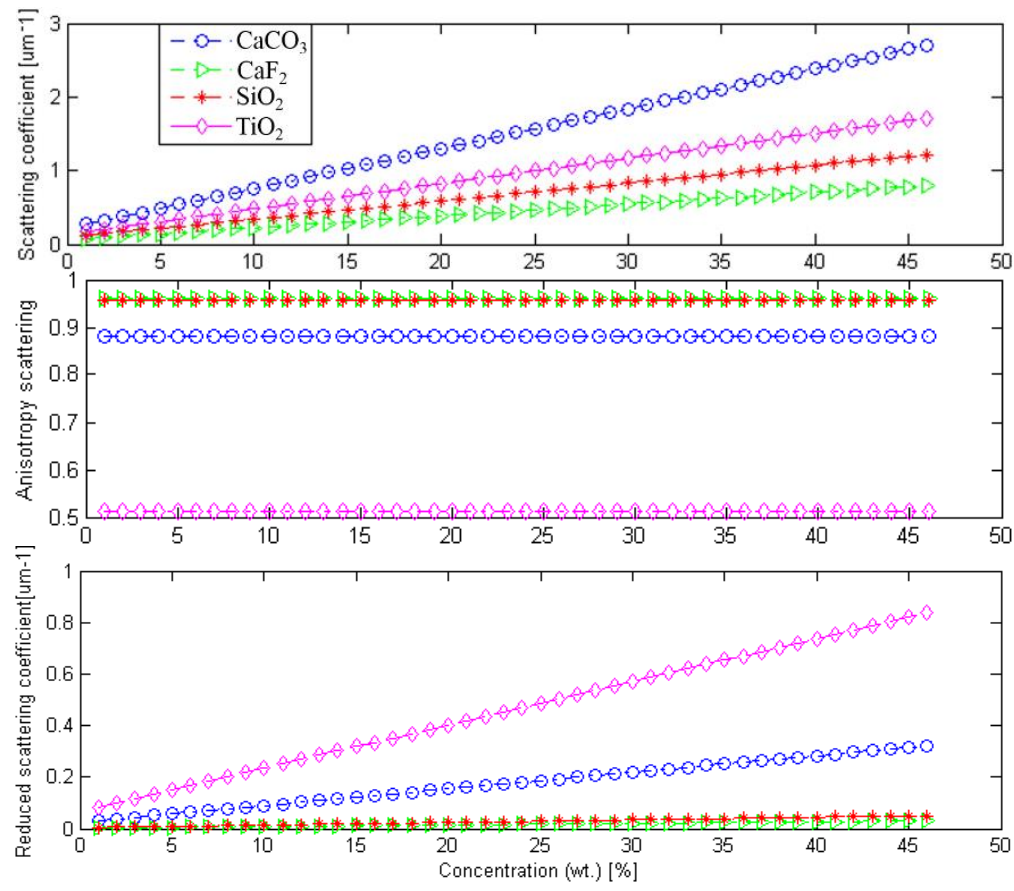

Figure 1. Computation of scattering coefficient, anisotropic scattering and reduced scattering coefficient of the SEPs at $455 \mathrm{~nm}$ 

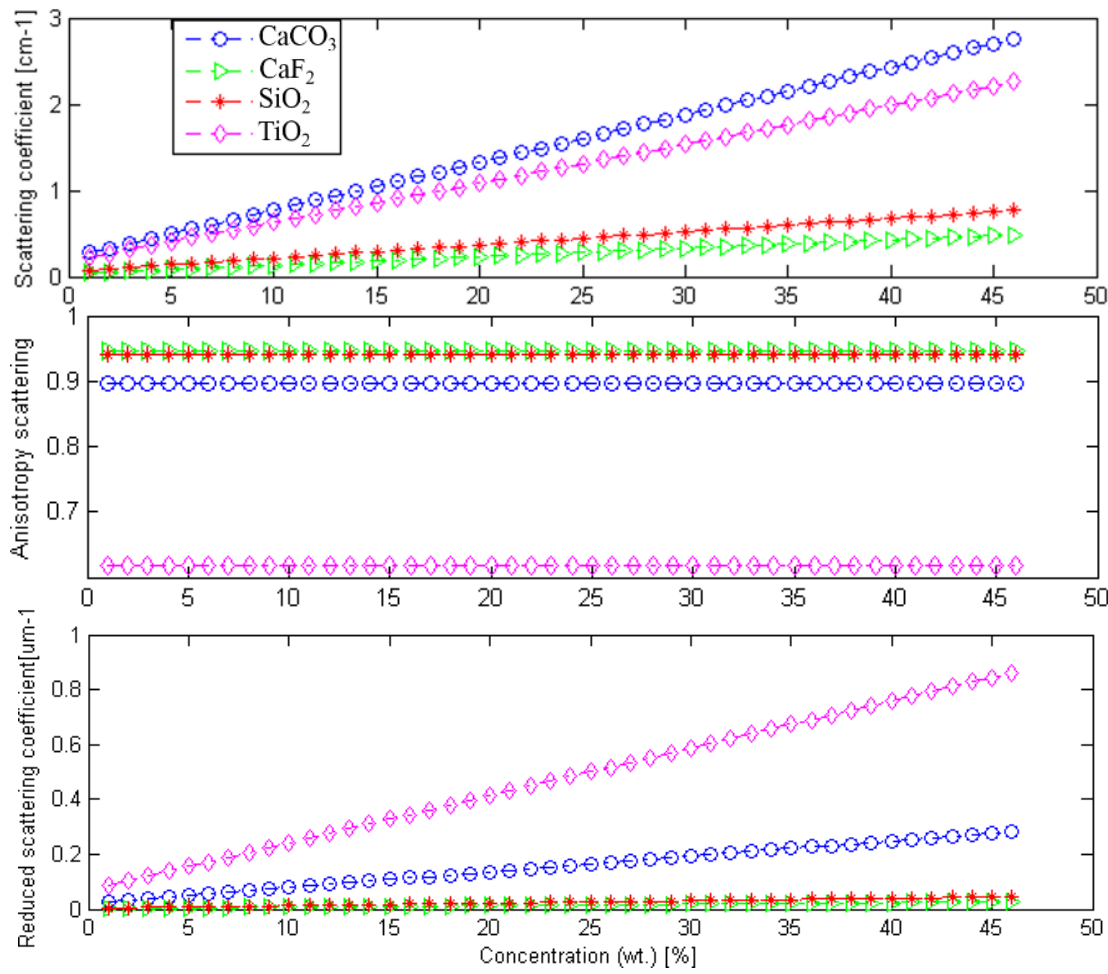

Figure 2. Computation of scattering coefficient, anisotropic scattering and reduced scattering coefficient of the SEPs at $595 \mathrm{~nm}$

Generally, the diminished dissipating coefficients of SEPs of $455 \mathrm{~nm}$ and 595nm wavelengths is practically comparable. For instance, $\mathrm{CaCO}_{3}$ has 0.9 as anisotropy factor at $595 \mathrm{~nm}$ and 0.8 at $455 \mathrm{~nm}$, which is not a huge discrepancy. Thus, the improvement of spatial shading consistency with the dissipating security of $\mathrm{CaCO}_{3}$ and $\mathrm{TiO}_{2}$ particles can occur without much of a stretch. Next, in Figure 3 is a description of the precise dissipating amplitudes of SEPs, which are processed by MATLAB program. It is clear that SEPs are extraordinary matters for blue-light dissipating as a result of the adequate pay for blue light, the effectiveness of SEPs in improving color quality and light output. The chosen SEPs that have precise dissipating wavelength in the middle of $455 \mathrm{~nm}$ in blue-light and $495 \mathrm{~nm}$ in yellow-light plays an important role in deciding the extent of positive effect. Contrasted to $\mathrm{SiO}_{2}, \mathrm{CaCO}_{3}$ with rakish dissipating wavelengths grains exhibit lesser distinction amidst the range of $455-595 \mathrm{~nm}$.

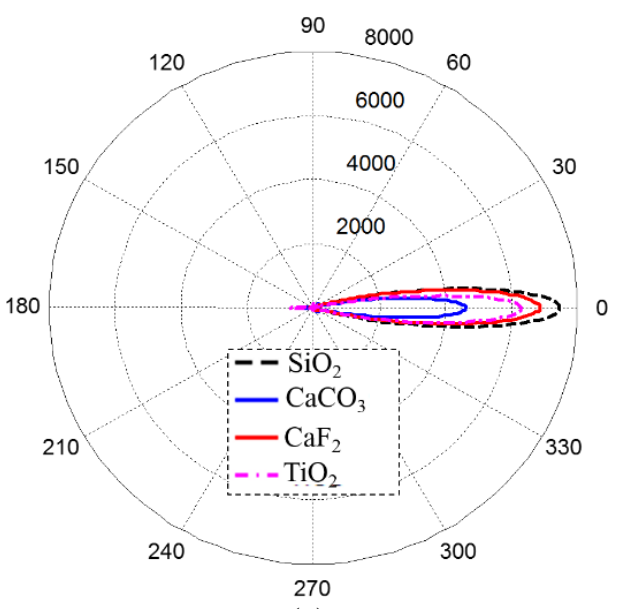

(a)

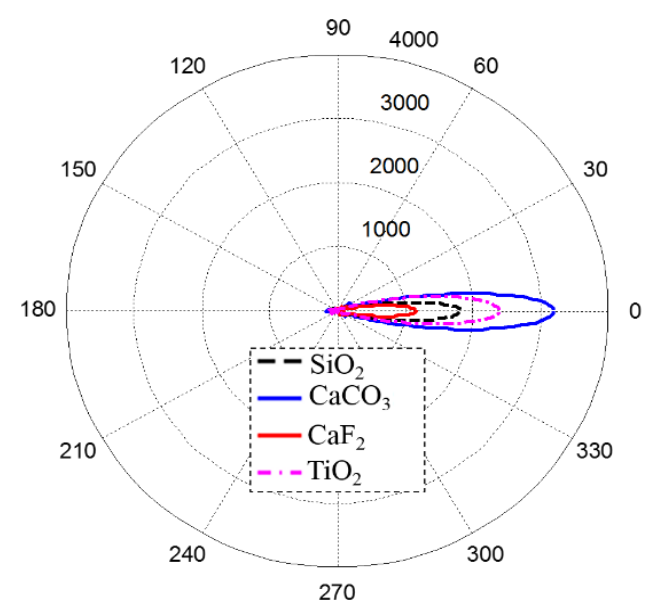

(b)

Figure 3. Angular scattering amplitudes of different SEPs at (a) $455 \mathrm{~nm}$ and (b) $595 \mathrm{~nm}$ 


\section{COMPUTATION AND DISCUSSION}

This part evaluate the light performance of SEPs in pc-LEDs configuration, which can be acquired by employing the LightTools 8.1.0 software. In Figure 4, the illustration of the schematic diagram of pc-LEDs is presented. The measurement of the LED reflector are approximately $2.1 \mathrm{~mm}$ depth, $8 \mathrm{~mm}$ inner diameter, and $10 \mathrm{~mm}$ outer diameter.

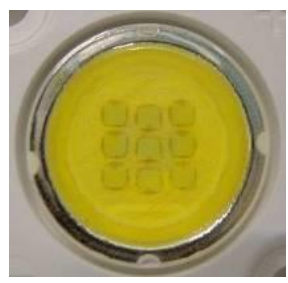

(a)

Lead frame: $4.7 \mathrm{~mm}$ Jentech Size-S LED chip: $\mathrm{V} 45 \mathrm{H}$ Die attach: Sumitomo 1295SA Gold Wire: $1.0 \mathrm{mil}$ Phosphor: ITC NYAG4_EL

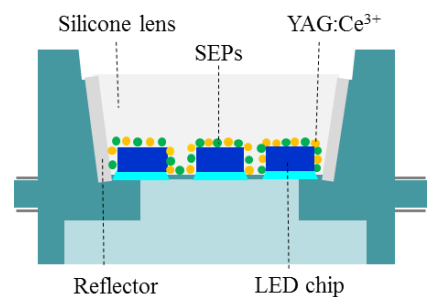

(c)

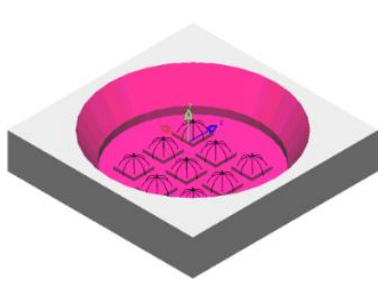

(d)

Figure 4. (a) Photograph of WLEDs sample, (b) manufacturing parameter of WLEDs,

(c) illustration of 2D WLEDs model, and (d) the simulated WLEDs model

The phosphor layer has predetermined density of $0.08 \mathrm{~mm}$ is used to coat 9 chips. The index of refraction for $\mathrm{CaCO}_{3}, \mathrm{CaF}_{2}, \mathrm{SiO}_{2}$, and $\mathrm{TiO}_{2}$, is $1.66,1.44,1.47$, and 2.87, respectively. It is assumed that all the SEPs are spherical and own the radius of $0.5 \mu \mathrm{m}$. Meanwhile, each phosphor grain has $7.25 \mu \mathrm{m}$ average radius, and 1.83 refractive index at all wavelengths in visible range. In addition, the silicone glue owns the refractive index of 1.5. To optimize the uniformity of CCT and the efficiency of lumen output, the value of the diffusional particle density is various.

$$
W_{\text {phosphor }}+W_{\text {silicone }}+W_{S E P}=100 \%
$$

In (6) is the percentage composition of a pcLEDs, where $W_{\text {silicone }}, W_{\text {phosphor }}$ and $W_{S E P}$, in turn, demonstrate the weight proportion of the silicone, phosphor and SEP in the phosphor composition of the structure. The balance between proportions of phosphor and SEP will result in CCT stability that keep it at $8500 \mathrm{~K}$. The color deviation is an important feature that indicate the quality of the lighting device. In lighting applications that use light-emitting diodes (LEDs), if the variation of CCT is high at different angles means that the yellow ring phenomenon will occur together with inhomogeneous white light causing the lighting performance of pcLEDs to decline. To calculate the CCT deviation the following expression can be applied:

$$
D-C C T=C C T_{(\operatorname{Max})}-C C T_{(\operatorname{Min})}
$$

In this equation, $\mathrm{CCT}_{(\mathrm{Max})}$ and $\mathrm{CCT}_{(\mathrm{Min})}$ in turns, denote the highest and lowest $\mathrm{CCT}$ at 0 and 90 degrees point of view.

In fact, the cause of variations in lighting qualities of pc-LEDs is the distinction among the dissipated light of every molecule in pc-LEDs. However, the main point here is that it is possible to get this CCT deviation decreased by improving the dispersed blue light adequately. According to the illustrations Figure 3 , it is obvious that at both $455 \mathrm{~nm}$ and $595 \mathrm{~nm}$ wavelengths, $\mathrm{CaCO}_{3}$ grains shows the smallest deviation of rakish dispersing abundance, compared to the other SEPs. This means using $\mathrm{CaCO}_{3}$ results in lowest color deviation during scattering process of LED chips light and the yellow-emitting phosphor. Additionally, different from all other SEPs, the angular scattering amplitude at $595 \mathrm{~nm}$ of $\mathrm{CaCO}_{3}$ particles is better than the result at $455 \mathrm{~nm}$. The combination of blue and yellow light fabricates white light but will also induce the "yellow ring" if the discrepancy between these chromatic lights are high enough, therefore, having enough blue light makes CCT deviation more manageable and eradicates yellow ring. On the other hand, the deviation of CCT will increase when the lack or excess of dispersed blue light in pc-LEDs occur. Likewise represented in Figure 3, the proportion of rakish dissipating amplitudes between $455 \mathrm{~nm}$ and $595 \mathrm{~nm}$ of the other SEPs, including $\mathrm{SiO}_{2}, \mathrm{CaF}_{2}$ and $\mathrm{TiO}_{2}$, is roughly multiple times. Along these lines, it is helpful in controlling the shading homogeneity and the radiant transition. Figure 5 shows the trends of CCT deviation according to different SEP concentration, which can completely demonstrate all the findings discussed above. Specifically, with the participation of $\mathrm{CaCO}_{3}$ and $\mathrm{TiO}_{2}$, the $\mathrm{CCT}$ deviations have downward tendencies. The color deviation in pc-LEDs without SEPs is $2670 \mathrm{~K}$, while with $30 \% \mathrm{CaCO}_{3}$, it is possible 
for the CCT deviation to decrease and reach the lowest value of $2050 \mathrm{~K}$. Therefore, we can conclude that using 30\% concentration of $\mathrm{CaCO}_{3}$, the CCT deviation can decline by $620 \mathrm{~K}$. Besides, the CCT deviation when there is $30 \% \mathrm{TiO}_{2}$ concentration is two times smaller than that without the participation of $\mathrm{TiO}_{2}$. In the cases of employing $\mathrm{CaF}_{2}$ and $\mathrm{SiO}_{2}$, the growth of CCT deviations along with both particles' concentration can be clearly observed. These findings provide the concrete fundament for using the mentioned SEPs to produce better WLED generations

The luminous outputs are presented in Figure 6 in accordance with the size and concentration of 4 SEPs. The concentrations of the SEPs are controlled from $0 \%$ to $50 \%$, and the particle size is adjusted from $100 \mathrm{~nm}$ to $1000 \mathrm{~nm}$. For $\mathrm{CaCO}_{3}$ and $\mathrm{SiO}_{2}$, it is easy to see that luminous flux increases with concentration and particle size. For $\mathrm{CaF}_{2}$ particles, luminous flux increases in the range of $0-20 \%$ for all particle sizes. Then, photocatalyst tends to decrease when the $\mathrm{CaF}_{2}$ concentration continues to rise. However, it is obvious that the larger the particle size is, the lower the scattering events in the phosphor layer occur. This leads to higher throughput of WLEDs. Similar to $\mathrm{CaF}_{2}$, the luminous flux of WLEDs in the case of $\mathrm{TiO}_{2}$ increased in the range of $0-10 \%$, then decreased significantly when the concentration increased for all particle sizes. In order to explain the reduction of luminous flux when increasing SEPs concentration, Lambert-Beer's law and Mie theory are applied.

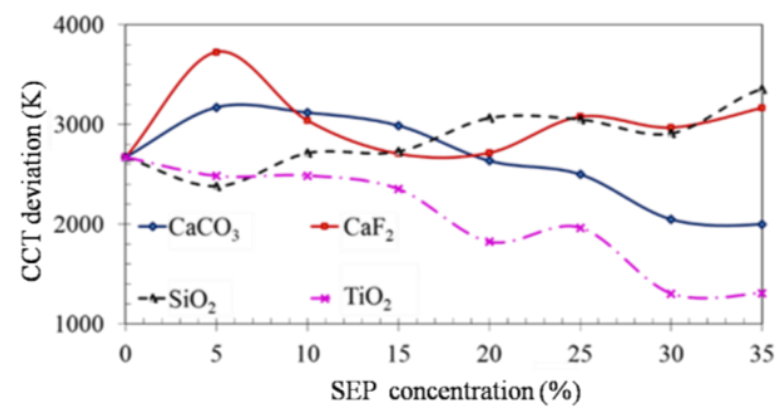

Figure 5. Comparison of CCT deviation of pc-LEDs using different SEPs

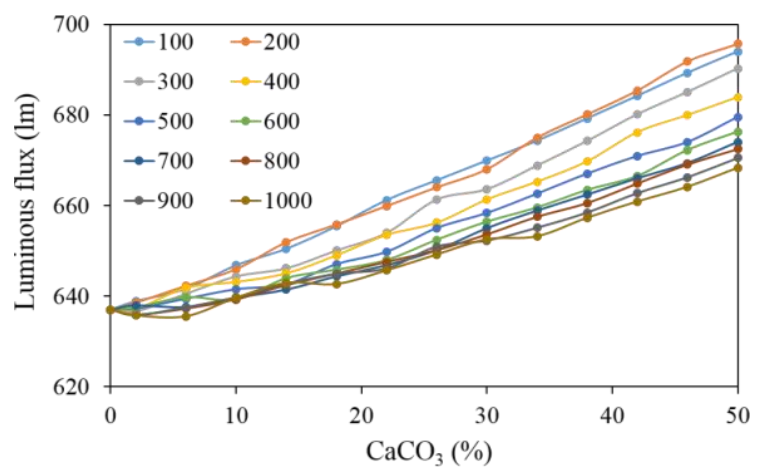

(a)

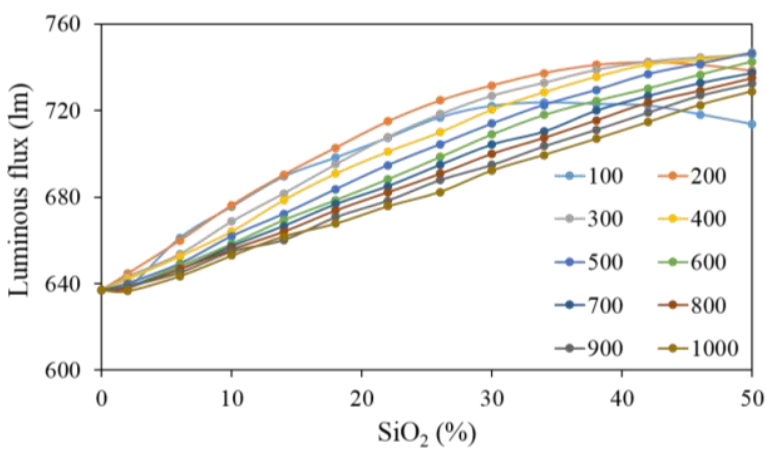

(c)

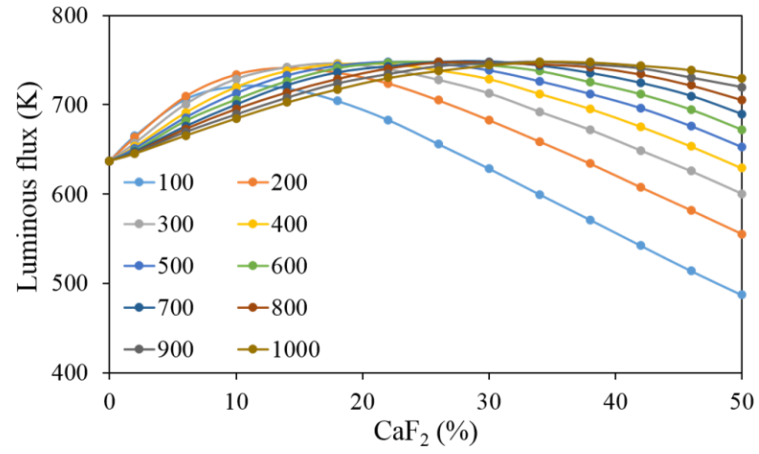

(b)

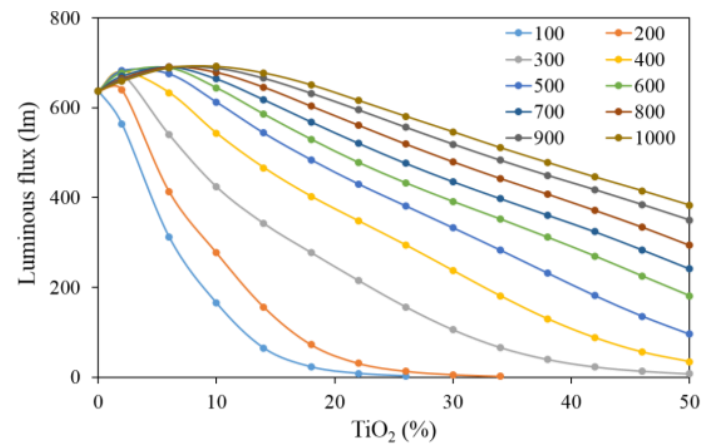

(d)

Figure 6. Comparison of luminous flux of pc-LEDs using different SEPs: (a) $\mathrm{CaCo}_{3}$, (b) $\mathrm{CaF}_{2}$, (c) $\mathrm{SiO}_{2}$, and (d) $\mathrm{TiO}_{2}$ 
The Mie-theory is employed for analyzing the scattering of SEPs, specifically the scattering cross section $C_{s c a}$ for spherical particles while the transmitted light power is analyzed using the Lambert-Beer law:

$$
I=I_{0} \exp \left(-\mu_{\text {ext }} L\right)
$$

According to the formula above, $I_{0}$ is the optical power of incident light and $L$ is the density of phosphor coating $(\mathrm{mm}) . \mu_{e x t}$ indicates the extinction coefficient that is computed by this equation: $\mu_{e x t}=N_{r}$. $C_{e x t}$, where $N_{r}$ stands for the number density distribution of particles $\left(\mathrm{mm}^{-3}\right)$ and $C_{\text {ext }}\left(\mathrm{mm}^{2}\right)$ is the extinction cross-section of phosphor particles. Based on (8), it can be concluded that the greater the concentration of SEPs, the less luminous flux of WLEDs. This can be explained by the reduction of light energy transmission by two reasons: one is that the energy transfer is reduced due to excessive scattering in the phosphor layer; and the other is the following scattering increases along with SEPs concentration.

\section{CONCLUSION}

In summary, our study is the first one analyzing impacts of different SEPs on two optical parts of pc-LEDs, chromatic homogeneity and luminous efficacy. Through the application of Mie-scattering and Monte Carlo in the experimenting process, the effectiveness and differences in light scattering enhancement using each type of SEPs in pc-LEDs can be confirmed. This achievement exposes us to a new effective method in managing the optical properties of pc-LEDs which is selecting appropriate SEPs corresponding to appropriate concentration. The results show that the CCT deviation is minimized when there is an increase in $\mathrm{CaCO}_{3}$ and $\mathrm{TiO}_{2}$ concentrations. Particularly, with $\mathrm{TiO}_{2}$ particles, we can accomplish the smallest color deviation value. Nevertheless, it shows a considerable reduction of emitted luminous flux when $\mathrm{TiO}_{2}$ concentration increase excessively. Meanwhile, the lumen output goes up as the $\mathrm{CaCO}_{3}$, $\mathrm{CaF}_{2}$ and $\mathrm{SiO}_{2}$ are added to the phosphor layer. Especially, $\mathrm{SiO}_{2}$ proves its advantage when showing higher lumen value than others. Meanwhile, the CCT deviation can be reduced by nearly $620 \mathrm{~K}$ if the concentration of $\mathrm{CaCO}_{3}$ is $30 \%$. Hence, using $\mathrm{CaCO}_{3}$ particles is to enhance the optical performance of pc-LEDs in most cases is the optimal option. With the findings exhibits in this paper, manufacturers can consider the benefits and the drawbacks of each types of SEPs, then determined which one is the most appropriate phosphor particle for their required LEDs.

\section{REFERENCES}

[1] D. Malviya, et al., "Ultrasound assisted synthesis of $\mathrm{CaF}_{2}: \mathrm{Eu}^{3+}$ phosphor nanoparticles," Luminescence, vol. 34, no. 4, pp. 426-431, 2019.

[2] S. K. Abeysekera, et al., "Impact of circadian tuning on the illuminance and color uniformity of a multichannel luminaire with spatially optimized LED placement," Opt. Express, vol. 28, no. 1, pp. 130-145, 2020.

[3] Y. G. Zhou, et al., "Comparison of nonlinear equalizers for high-speed visible light communication utilizing silicon substrate phosphorescent white LED," Opt. Express, vol. 28, no. 2, pp. 2302-2316, 2020.

[4] H. S. El-Ghoroury, et al., "Color temperature tunable white light based on monolithic color-tunable light emitting diodes," Opt. Express, vol. 28, no. 2, pp. 1206-1215, 2020.

[5] H. K. Park, et al., "Toward scatter-free phosphors in white phosphor-converted light-emitting diodes," Optics Express, vol. 20, no. 9, pp. 10218-10228, 2012.

[6] J. H. Oh, et al., "Analysis of wide color gamut of green/red bilayered freestanding phosphor film-capped white LEDs for LCD backlight," Optics Express, vol. 23, no. 15, pp. A791-A804, 2015.

[7] S. P. Ying, et al., "Curved remote phosphor structure for phosphor-converted white LEDs," Applied Optics, vol. 53, no. 29, pp. H160-H164, 2014.

[8] M. T. Wang and J. M. Huang, "Accurate control of chromaticity and spectra by feedback phosphor-coating," Optics Express, vol. 23, no. 9, pp. 11576-11585, 2015.

[9] S. N. Kim, et al., "Relationship between phosphor properties and chromaticity of phosphor-in-glass," Applied Optics, vol. 56, no. 34, pp. 9477-9483, 2017.

[10] G. F.J. Garlick, A. F. Gibson, "The Luminescence of Photo-Conducting Phosphors," Journal of the Optical Society of America. vol. 39, no. 11, pp. 935-941, 1949.

[11] S. P. Ying, A. Y. Shiu, "Investigation of remote-phosphor white light-emitting diodes with improved scattered photon extraction structure," Applied Optics, vol. 54, no. 28, pp. E30-E34, 2015.

[12] W. J. Kim, et al., "Improved angular color uniformity and hydrothermal reliability of phosphor-converted white light-emitting diodes by using phosphor sedimentation," Optics Express, vol. 26, no. 22, pp. 28634-28640, 2018.

[13] R. T. Velpula, et al., "Numerical investigation on the device performance of electron blocking layer free AlInN nanowire deep ultraviolet light-emitting diodes," Opt. Mater. Express, vol. 10, no. 2, pp. 472-483, 2020.

[14] V. V. Bakhmet'ev, et al., "Synthesis of finely dispersed $\mathrm{NaBaPO}_{4}: \mathrm{Eu}^{2+}$ phosphors and structural investigation of their centers of luminescence," Journal of Optical Technology, vol. 84, no. 9, pp. 642-646, 2017. 
[15] H. F. Sijbom, et al., " $\mathrm{K}_{2} \mathrm{SiF}_{6}: \mathrm{Mn}^{4+}$ as a red phosphor for displays and warm-white LEDs: a review of properties and perspectives," Optical Materials Express, no. 9, vol. 7, pp. 3332-3365, 2017.

[16] S. Bharadwaj, et al., "Enhanced injection efficiency and light output in bottom tunnel-junction light-emitting diodes," Opt. Express, vol. 28, no. 4, pp. 4489-4500, 2020.

[17] L. Y. Chen, et al., "Novel broadband glass phosphors for high CRI WLEDs," Optics Express, vol. 22, no. 103, pp. A671-A678, 2014.

[18] A. Pandey, et al., "Effect of electron blocking layer on the efficiency of AlGaN mid-ultraviolet light emitting diodes," Opt. Express, vol. 27, no. 12, pp. A738-A745, 2019.

[19] B. Jain, et al., "High performance electron blocking layer-free InGaN/GaN nanowire white-light-emitting diodes," Opt. Express, vol. 28, no. 1, pp. 665-675, 2020.

[20] J. W. Moon, et al., "Optical characteristics and longevity of the line-emitting $\mathrm{K}_{2} \mathrm{SiF}_{6}: \mathrm{Mn}^{4+}$ phosphor for LED application," Optical Materials Express, no. 3, vol. 6, pp. 782-792, 2016.

[21] B. Li, et al., "High-efficiency cubic-phased blue-emitting $\mathrm{Ba}_{3} \mathrm{Lu}_{2} \mathrm{~B}_{6} \mathrm{O}_{15}: \mathrm{Ce}^{3+}$ phosphors for ultraviolet-excited white-light-emitting diodes," Optics Letters, vol. 43, no. 20, pp. 5138-5141, 2018.

[22] J. W. Jang, et al., "UV-curable silicate phosphor planar films printed on glass substrate for white light-emitting diodes," Optics Letters, vol. 40, no. 16, pp. 3723-3726, 2015.

[23] J. Belin, et al., "Hybrid absorption/interference wide-angle filter using PECVD Si-Rich SixNy and SiOx for LED lighting," Opt. Express, vol. 27, no. 9, pp. 12519-12528, 2019.

[24] A. X. Guan, et al., "Photoluminescence Properties and Energy Transfer of $\mathrm{Eu}^{3+}, \mathrm{Bi}^{3+}$ Co-Doped $\mathrm{Ca}_{9}\left(\mathrm{PO}_{4}\right)_{7}$ Phosphors," Journal of Display Technology, vol. 12, no. 2, pp.136-142, 2016.

[25] X. R. Ding, et al., "Improving the optical performance of multi-chip LEDs by using patterned phosphor configurations," Optics Express, vol. 26, no. 6, pp. A283-A292, 2018. 